\title{
Does early removal of double J stents reduce urinary infection in living donor renal transplantation?
}

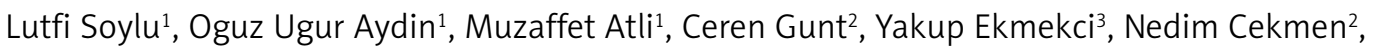
Sedat Karademir ${ }^{1}$

\author{
${ }^{1}$ Department of General Surgery and Organ Transplantation, Ankara Güven Hastanesi, \\ Ankara, Turkey \\ 2Department of Anesthesiology and Reanimation, Ankara Güven Hastanesi, Ankara, \\ Turkey \\ ${ }^{3}$ Department of Nephrology, Ankara Güven Hastanesi, Ankara, Turkey
}

Submitted: 23 December 2017

Accepted: 24 January 2018

Arch Med Sci 2019; 15, 2: 402-407

DOI: https://doi.org/10.5114/aoms.2018.73524

Copyright @ 2018 Termedia \& Banach

\begin{abstract}
Introduction: Prophylactic use of double J (DJ) stents in recipients is highly accepted in renal transplantation. In this study, the association between the frequency of urologic complications (UC) and urinary tract infections (UTI), and the early or late removal of DJ stents was investigated.

Material and methods: A total of 116 live-donor renal transplant patients were included in the study during a 4-year period, with a mean follow-up of $29.2 \pm 15.3$ months. In all, DJ stents were used. All patients were clinically monitored for graft function by assessment of the complete blood count, renal biochemistry, urine analysis and blood drug level according to our follow-up protocol.

Results: The patients were divided into 2 groups according to the time of their stent removal: group I $(n=44)$, removal within the first 14 days; and group II $(n=72)$, removal after 14 days. No urinary leaks were detected in either of the groups. Three patients suffered from anastomotic stricture (group I, $n=1$; group II, $n=2$ ). The rates of UTI were similar in groups I and II $(13.6 \%$ vs. $16.6 \%$, respectively, $p=0.79)$. The rate of UTI in women was found to be 3.8 times higher than in men.

Conclusions: The results of our study demonstrated that DJ stent removal within 14 days did not reduce the risk of UTI when compared to stent removal after 14 days. Similar effects on complication rates for ureteral stenting for these 2 removal periods were observed.
\end{abstract}

Key words: kidney transplantation, urinary tract infection, catheter.

\section{Introduction}

Renal transplantation is the most effective and curative treatment for patients with end-stage renal disease [1]. However, transplantation usually results in urinary complications (UC) such as urine leak, vesicoureteral reflux, stricture, and ureteric obstruction. To prevent such complications, the placement of double J (DJ) stents is a common prophylaxis during ureteral anastomosis [2-7]. However, an increase in urinary tract infections (UTI) and hematuria has been observed with the use of DJ stents following transplantation [8].

Double J stents are usually removed 4 to 6 weeks after surgery. However, it has been reported that removing the DJ stents earlier than this may

\author{
Corresponding author: \\ Dr. Lütfi Soylu \\ Ankara Güven Hastanesi \\ Çiftevler Sokak \\ 5/13 Aşagı Ayrancı \\ 06540 Ankara, Turkey \\ Phone: +90 3124572473 \\ Fax: +90 3124572886 \\ E-mail: lutfisoylu@hotmail.com
}


result in a decreased risk of complications such as UTI and persistent hematuria, which would also reduce the hospitalization duration as well [9]. However, the ideal timing for DJ stent removal is still controversial and the exact time has not yet been determined [10-16].

In our study, we retrospectively analyzed the role of the DJ stents and their removal times in terms of the associated UTI and UC after transplantation.

\section{Material and methods}

In this study, we reviewed the clinical outcomes of 125 consecutive live-donor renal transplant recipients over a 4-year period. In all, a DJ stent was placed during ureteroneocystostomy. The exclusion criteria included double-collective urinary system $(n=2)$, patients who had graft nephrectomy before stent removal $(n=1)$, and a Foley catheter left for more than 5 days $(n=5)$. One patient who had the diagnosis of UTI on postoperative day 3 was also excluded for suspected violation of asepsis during insertion of the Foley catheter. In total 116 patients who were followed in accordance with the acceptance protocol were included in the study.

Transplantations were performed by the same surgical team. The kidneys were harvested from living donors using a laparoscopic technique. In the recipients, the entire genital area was cleaned with an iodine-based solution and a Foley catheter was inserted before the operation. The bladder was filled with $150 \mathrm{ml}$ of isotonic solution containing $1 \mathrm{~g}$ of first-generation cephalosporin. The renal graft was placed in the iliac cavity, close to the previously dissected external iliac vessels. Anastomosis of the renal vein to the common or external iliac vein and renal artery to the internal or external iliac artery were performed. All of the DJ stents were $6 \mathrm{Fr} 15 \mathrm{~cm}$ and made of polyurethane. Ureteroneocystostomy was performed using the Lich-Gregoir method. A closed-suction drainage system was placed in every patient.

Induction immunosuppression included calcineurin inhibitor (tacrolimus), mycophenolate mofetil, and steroid. The peritransplant antibiotic prophylaxis consisted of a single dose of first-generation cephalosporin (cefazolin) before the induction of anesthesia. In terms of the postoperative prophylaxis, only a 480-mg daily dose of trimethoprim/sulfamethoxazole (TMP/SMX) was given for a period of 3 months.

The Foley catheters were removed postoperatively on day 5. A urine sample for a urine analysis and culture was obtained before the Foley catheter was removed. A positive result for UTI was considered when the bacterial counts were recorded as more than $10^{5}$ bacterial colony-forming units per milliliter (CFU/ml) on the urine culture.

Following discharge, patients were clinically monitored for graft function by assessing the complete blood count, renal biochemistry, urine analysis, and blood drug level every week for the first month, biweekly for 2 months and with decreasing frequency thereafter. Patients are seen twice annually after the third year of transplantation.

Unless otherwise indicated, DJ stents are scheduled for removal at 2 weeks after transplantation. However, due to different reasons (cultural, economic and logistic, etc.), patients' compliance with follow-up appointments have been loose. This has led to a series with variations in timing of stent removal. Stents are removed under aseptic conditions and no additional antibiotic is used at the time of cystoscopy.

Only UTI within the first 3 postoperative months were considered. An antibiotic sensitivity test was performed for all of the urine cultures and the pathogen susceptibility was obtained. All of the urine cultures were processed in the same laboratory. Patients with UTI were treated according to their antibiotic sensitivity test result. Stent removal was performed under aseptic conditions and no additional antibiotics were used at the time of cystoscopy and stent removal.

The patients were divided into 2 groups according to the time of stent removal: group I $(n=44)$, before 14 days, and group II $(n=72)$, after 14 days. The groups were compared in terms of the age, gender, and body mass index (BMI) of both the donor and recipient etiology of renal failure, cold ischemia time, rate of UTI and UC as well as glomerular filtration rates (GFR) at three months after transplantation and the latest follow-up.

\section{Statistical analysis}

Analysis of the data was done using the IBM SPSS 23.0 and MedCalc 15.8 statistical package programs. The chi-square test was used to compare the descriptive statistics (frequency, percentage, mean, standard deviation, median, and minmax) and the qualitative data when evaluating the study data. The normal distribution of the data was evaluated using the Kolmogorov-Smirnov and Shapiro-Wilk tests. In the study, the independent samples $t$ ( $t$ test in independent groups) and 1-way ANOVA (analysis of variance) tests were used in the comparison between the groups. Values of $p<0.05$ were considered as statistically significant.

\section{Results}

A total of 116 live-donor renal transplant patients were included in the study over a 4-year pe- 
Table I. Demographic and clinical characteristics of the 2 groups

\begin{tabular}{|lccc|}
\hline Parameter & Group I $(n=44)$ & Group II $(n=72)$ & $P$-value \\
\hline Age & $45.6 \pm 14.8$ & $44.6 \pm 12.9$ & $0.698^{\mathrm{a}}$ \\
\hline \begin{tabular}{l} 
Sex: \\
\hline Female
\end{tabular} & $13(29.5 \%)$ & $16(22.2 \%)$ & $0.386^{\mathrm{b}}$ \\
\hline Male & $31(70.5 \%)$ & $56(77.8 \%)$ & \\
\hline BMI [kg/m² & $25.9 \pm 4.6$ & $27.0 \pm 4.9$ & $0.955^{\mathrm{a}}$ \\
\hline CIT [min] & $46.2 \pm 6.6$ & $45.1 \pm 6.8$ & $0.620^{\mathrm{a}}$ \\
\hline Follow-up [months] & $33.6 \pm 15.3$ & $26.5 \pm 14.1$ & $0.019^{\mathrm{a}}$ \\
\hline DM & $21(47.7 \%)$ & $26(36.1 \%)$ & $0.240^{\mathrm{b}}$ \\
\hline HT & $12(27.3 \%)$ & $24(33.3 \%)$ & $0.540^{\mathrm{b}}$ \\
\hline Idiopathic & $7(15.9 \%)$ & $15(20.8 \%)$ & $0.628^{\mathrm{b}}$ \\
\hline Glomerulonephritis & $2(4.5 \%)$ & $4(5.6 \%)$ & $1.000^{\mathrm{b}}$ \\
\hline PKD & $2(4.5 \%)$ & $3(4.2 \%)$ & $1.000^{\mathrm{b}}$ \\
\hline Donor age & $45.9 \pm 14.3$ & $46.6 \pm 13.1$ & $0.810^{\mathrm{a}}$ \\
\hline Donor sex: & $27(54.5 \%)$ & $32(44.5 \%)$ & $0.682^{\mathrm{a}}$ \\
\hline Female & $20(43.5 \%)$ & $27.4 \pm 5.8$ & $1.000^{\mathrm{b}}$ \\
\hline Male & $27.6 \pm 5.6$ & $40(55.5 \%)$ & \\
\hline Donor BMI & & & \\
\hline
\end{tabular}

alndependent samples $t$ test, ${ }^{b} \chi^{2}$ test. PKD - polycystic kidney disease, BMI-body mass index, $H T$ - hypertension, DM - diabetes mellitus, CIT - cold ischemia time.

riod, with a mean follow-up of $29.2 \pm 15.3$ months. Demographic details of the renal recipients, donors and transplants are presented in Table I. There were no significant differences between the 2 groups, except for the length of the follow-up $(p=0.019)$.

The DJ stents were removed after a mean of $12.2 \pm 3$ days in group I and $26.4 \pm 11.8$ days in group II (Table II). In group I, the DJ stents were removed prematurely in 5 patients due to persistent hematuria. No urinary leaks were detected in either of the groups. A total of 3 patients suffered from anastomotic stricture (group I, $n=1$; group II, $n=2$ ). The latter 2 underwent stent replacement at 27 days and 90 days, postoperatively. The remaining patient underwent ureteroneocystostomy on postoperative day 70 .

The rates of UTIs were similar in groups I and II (13.6\% vs. $16.6 \%$, respectively, $p=0.79$ ). The most common microorganisms detected in the UTIs, in order of frequency, included Escherichia coli $(n=10)$, Klebsiella pneumoniae $(n=3)$, Staphylococcus $(n=3)$, Candida spp. $(n=1)$, and Enterococ-

Table II. Post-transplant complication rates, UTI and GFRs in the 2 groups

\begin{tabular}{|c|c|c|c|}
\hline Parameter & $\begin{array}{l}\text { Group I } \\
(n=44)\end{array}$ & $\begin{array}{l}\text { Group II } \\
(n=72)\end{array}$ & $P$-value \\
\hline Stent removal (PO days) & $12.2 \pm 3.0$ & $26.4 \pm 11.8$ & \\
\hline UTI & $6(13.6 \%)$ & $12(16.6 \%)$ & $0.790^{\mathrm{b}}$ \\
\hline \multicolumn{4}{|l|}{ Urinary complication: } \\
\hline Stricture & $1(0.02 \%)$ & $2(0.02 \%)$ & $1.000^{\mathrm{b}}$ \\
\hline Leakage & None & None & \\
\hline GFR (post*transplant $3^{\text {rd }}$ month) & $71.4 \pm 20.3$ & $65.0 \pm 23.1$ & $0.121^{a}$ \\
\hline GFR (latest) & $68.3 \pm 18.3$ & $65.3 \pm 22.4$ & $0.436^{a}$ \\
\hline
\end{tabular}

aIndependent samples t test, ${ }^{b} \chi^{2}$ test. PO day - postoperative day, UTI - urinary tract infection, GFR - glomerular filtration rate. 
cus spp. $(n=1)$. None of these growths were found to be resistant strains.

The rate of UTIs in women was found to be 3.8 times higher than in men (OR $=3.815 ; 95 \%$, GA: 1.69-8.60). Including the stent removal time, there was no difference in the demographic and clinical features between those with and without UTI after transplantation (Table III).

In our series, 3 patients were started on renal replacement therapy at 15 days (acute rejection), 19 and 31 months (chronic rejection) after transplantation. Six recipients were lost within a median of 147 days (range: 84-930 days). Of these, the reasons for death were myocardial infarction in 2 , traffic accident in 1 and sepsis in 3.

\section{Discussion}

Urinary complications such as urinary leakage and anastomotic stricture at the ureteroneocystostomy site are inevitable. Prophylactic use of the DJ stent in recipients has been highly accepted in literature. However, stents may cause UTI, which lead to prolonged hospitalization, increased costs, and the need for recurrent surgical procedures $[17,18]$. There is no agreement of opinion among the centers about the optimal time of removal for the DJ stents postoperatively. In the literature, different researchers have reported varying results about the removal of DJ stents after 1 week to 3 months, postoperatively.

The use of routine prophylactic DJ stents was reported by Tavakoli et al. [4] and Wilson et al. [19] to reduce the occurrence of mechanical urological complications. However, Wilson concluded that the placement of a DJ stent correlates with the general risk of UTI, with 1.5 within 3 months of transplantation. Dominguez et al. [8], Parapiboon et al. [20], and Kumar et al. [21] suggested that removing the DJ stents earlier might result in a reduction in the incidence of UTI, with no risk to the ureteral anastomosis.

In contrast, Mathe et al. [22] reported UTI rates that were similar in stented (43.3\%) and non-stented patients (40.1\%). Shohab et al. [23] analyzed UTI incidence rates in recipients of stented and non-stented renal transplants and reported no differences $(R R=1.08)$.

Table III. Demographic and clinical features of the recipients with and without UTI after transplantation

\begin{tabular}{|c|c|c|c|}
\hline \multirow[t]{2}{*}{ Parameter } & \multicolumn{2}{|c|}{ Urinary tract infection } & \multirow[t]{2}{*}{$P$-value } \\
\hline & No $(n=98)$ & Yes $(n=18)$ & \\
\hline Age & $44.2 \pm 14.0$ & $45.4 \pm 10.7$ & $0.346^{a}$ \\
\hline \multicolumn{4}{|l|}{ Sex: } \\
\hline Female & $20(20.4 \%)$ & $10(55.5 \%)$ & \multirow[t]{2}{*}{$0.006^{b}$} \\
\hline Male & $78(79.6 \%)$ & $8(44.5 \%)$ & \\
\hline BMI & $26.0 \pm 4.8$ & $24 \pm 4.4$ & $0.427^{\mathrm{a}}$ \\
\hline CIT & $45.2 \pm 6.9$ & $46.8 \pm 6.7$ & $0.341^{a}$ \\
\hline Stent removal time [days] & $20.6 \pm 11.8$ & $22.3 \pm 11.5$ & $0.504^{\mathrm{a}}$ \\
\hline DM & $40(40.8 \%)$ & $8(42.1 \%)$ & $0.917^{b}$ \\
\hline HT & $28(28.6 \%)$ & $5(27.7 \%)$ & $0.787^{b}$ \\
\hline Idiopathic & $21(21.4 \%)$ & $3(15.8 \%)$ & $0.577^{b}$ \\
\hline Glomerulonephritis & $5(5.1 \%)$ & $1(5.3 \%)$ & $0.977^{b}$ \\
\hline PKD & $4(4.1 \%)$ & $1(5.3 \%)$ & $0.816^{\mathrm{b}}$ \\
\hline Donor age & $46.6 \pm 13.7$ & $43.2 \pm 12.4$ & $0.762^{a}$ \\
\hline \multicolumn{4}{|l|}{ Donor sex: } \\
\hline Female & $54(55.1 \%)$ & $9(50.0 \%)$ & \multirow[t]{2}{*}{$0.798^{b}$} \\
\hline Male & $44(44.9 \%)$ & $9(50.0 \%)$ & \\
\hline Donor BMI & $27.7 \pm 5.5$ & $24.2 \pm 6.0$ & $0.110^{\mathrm{a}}$ \\
\hline GFR (post-transplant $3^{\text {rd }}$ month) & $67.2 \pm 21.6$ & $63.3 \pm 25.6$ & $0.724^{a}$ \\
\hline GFR (current) & $66.4 \pm 21.4$ & $61.7 \pm 18.1$ & $0.571^{a}$ \\
\hline
\end{tabular}

alndependent samples $t$ test, ${ }^{b} \chi^{2}$ test. PKD - polycystic kidney disease, BMI - body mass index, HT - hypertension, DM - diabetes mellitus, UTI - urinary tract infection, CIT - cold ischemia time. 
Moreover, it was reported by Liu et al. [24] that removal of the DJ stents 1 week post-operatively reduced the risk of UTI when compared to results with the usual removal at 4 weeks. Verma et al. [18] and Yuksel et al. [25] made a recommendation of using a DJ stent for 14 days, which would greatly reduce the risk of complications when compared with usage for a longer period of time. In his research, Yuksel et al. [25] reported rates of UTI and UC of $1.4 \%$ and $5.1 \%$, respectively, and found that these low infection rates were likely due to long-term preoperative antibiotic use.

In our study, 18 of the 116 patients suffered from UTI within 3 months postoperatively (15.5\%). As was expected from the reports by Wojciechowski and Chandran [26] and Gozdowska et al. [27], our female recipients were found to have a higher occurrence of UTI than the males $(p=0.002)$. However, we found no significant difference in the risk of UTI between recipients who underwent DJ stent removal before and after postoperative day $14(13.6 \%$ vs. $16.6 \%$, respectively). None of our patients experienced leakage from urinary anastomosis. After $29.2 \pm 15.3$ months of follow-up, only $3(2.58 \%)$ patients suffered from anastomotic stricture, which resolved after re-stenting or surgery. In the literature, the UC rate has varied between $0.22 \%$ and $14 \%$ over the past 2 decades [18]. Our low rate of leakage may be related to a refined surgical technique and the use of a DJ stent at urinary anastomosis.

Antibiotic prophylaxis in a kidney transplant recipient may prevent UTI, but may also foster the selection of resistant strains. When an empirical treatment is applied, it has been observed that strains resistant to antibiotics frequently used in kidney transplant patients are more frequent. To avoid this resistance, in our patients, a perioperative antibiotic protocol that consisted of a single dose of cefazolin ( $1 \mathrm{~g}$ ) was given prior to incision. Thereafter, only TMP/SMX was given on a daily basis. We did not experience any graft loss associated with the UTI. Moreover, no resistant microorganisms were detected in the urine cultures of the patients who developed UTI.

This study had several limitations. First, this was a retrospective study and randomization was not performed. Second, there were no recipients without a ureteric stent. However, a cohort of live-donor kidney recipients was included in this study and analyzed without prior selection. On the order hand, all of the patients had the same immunosuppressive regimen and comparable risk factors for the development of UTI.

In conclusion, the results of our study demonstrated that DJ stent removal within 14 days did not reduce the risk of UTI when compared with stent removal beyond 14 days. Similar effects of ureteric stent removal on the UC rates were observed for these 2 removal periods.

\section{Conflict of interest}

The authors declare no conflict of interest.

\section{References}

1. Aki FT, Koni A, Bilen CY, İnci K, Erkan I, Bakkaloğlu M. Management of encrusted uretral stent with mini percutaneous nephrolithotomy in patient with kidney transplantation. Turkish Nephrol Dial Transplant J 2010; 19: 65-8.

2. Yigit B, Tellioglu G, Berber I, et al. Surgical treatment of urologic complications after renal transplantation. Transplant Proc 2008; 40: 202-4.

3. Samhan M, Al-Mousawi M, Hayati H, Abdullahim M, Nampoory MR. Urologic complications after renal transplantation. Transplant Proc 2005; 37: 3075-6.

4. Tavakoli A, Surange RS, Pearson RC, Parrott NR, Augustine T, Riad HN. Impact of stents on urological complications and health care expenditure in renal transplant recipients: results of a prospective. Randomized clinical trial. J Urol 2007; 177: 2260-4.

5. Gomes G, Nunes P, Castelo D, et al. Ureteric stent in renal transplantation. Transplant Proc 2013; 45: 1099-101.

6. Sinangil A, Celik V, Barlas S, Akın EB, Ecder T. Should transplant ureter be stented routinely or not? Eur Rev Med Pharmacol Sci 2014; 18: 3551-6.

7. Mangus RS, Haag BW. Stented versus nonstented extravesical ureteroneocystostomy in renal transplantation: a metaanalysis. Am J Transplant 2004; 4: 1889-96.

8. Dominguez J, Clase CM, Mahalati K, et al. Is routineureteric stenting needed in kidney transplantation? A randomized trial. Transplantation 2000; 70: 597-601.

9. Coskun AK, Harlak A, Ozer T, et al. Is removal of the stent at the end of 2 weeks helpful to reduce infectious or urologic complications after renal transplantation? Transplant Proc 2011; 43: 813-5.

10. Mongha R, Kumar A. Transplant ureter should be stented routinely. Indian J Urol 2010; 26: 450-3.

11. Shivde SR, Date J, Dighe TA, Joshi PM. Unusual causes of obstruction to transplant ureter. Saudi J Kidney Dis Transplant 2010; 21: 310-3.

12. Ashraf HS, Khan MU, Hussain I, Hyder I. Urological complications in ureteric stenting live related renal transplantation. J Coll Physicians Surg Pak 2011; 21: 34-6.

13. DuBay DA, Lynch R, Cohn J, et al. Is routine ureteral stenting cost-effective in renal transplantation? J Urol 2007; 178: 2509-13.

14. Lojanapiwat B, Mital D, Fallon L, et al. Management of ureteral stenosis after renal transplantation. J Am Coll Surg 1994; 179: 21-4.

15. Minnee RC, Bemelman FJ, Laguna Pes PP, ten Berge IJ, Legemate DA, Idu MM. Effectiveness of a 5-day external stenting protocol on urological complications after renal transplantation. World I Surg 2009; 33: 2722-6.

16. Nicholson ML, Veitch PS, Donnelly PK, Bell PR. Urological complications of renal transplantation: the impact of double J ureteric stents. Ann R Coll Surg Engl 1991; 73: 316-21.

17. Ranganathan M, Akbar M, Ilham MA, Chavez R, Kumar N, Asderakis A. Infective complications associated with ureteral stents in renal transplant recipients. Transplant Proc 2009; 41: 162-4. 
18. Verma M, Bhandari A, Srivastava R, Kapoor R, Kumar A. Optimum duration of J.J. stenting in live related renal transplantation. Indian J Urol 2002; 19: 54-7.

19. Wilson CH, Rix DA, Manas DM. Routine intraoperative ureteric stenting for kidney transplant recipients. Cochrane data-base. Syst Rev 2013; 17: CD004925.

20. Parapiboon W, Ingsathit A, Disthabanchong S, et al. Impact of early ureteric stent removal and cost-benefit analysis in kidney transplant recipients: results of a randomized controlled study. Transplant Proc 2012; 44: 737-9.

21. Kumar A, Verma BS, Srivastava A, Bhandari M, Gupta A, Sharma R. Evaluation of the urological complications of living related renal transplantation at a single center during the last 10 years: impact of the double-J stent. J Urol 2000; 164: 657-60.

22. Mathe Z, Treckmann JW, Heuer M, et al. Stented ureterovesical anastomosis in renal transplantation: Does it influence the rate of urinary tract infections? Eur J Med Res 2010; 15: 297-302.

23. Shohab D, Khawaja A, Atif E, Jamil I, Ali I, Akhter S. Frequency of occurrence of urinary tract infection in double J stented versus non-stented renal transplant recipients. Saudi J Kidney Dis Transplant 2015; 26: 443-6.

24. Liu S, Luo G, Sun B, et al. Early removal of double-J stents decreases urinary tract infections in living donor renal transplantation: a prospective, randomized clinical trial. Transplant Proc 2017; 49: 297-302.

25. Yuksel Y, Tekin S, Yuksel D, et al. Optimal timing for removal of the double-J stent after kidney transplantation. Transplant Proc 2017; 49: 523-7.

26. Wojciechowski D, Chandran S. Effect of ciprofloxacin combined with sulfamethoxazole-trimethoprim prophylaxis on the incidence of urinary tract infections after kidney transplantation. Transplantation 2013; 96: 400-5.

27. Gozdowska J, Czerwinska M, Chabros L, et al. Urinary tract infections in kidney transplant recipients hospitalized at a transplantation and nephrology ward: 1-year follow-up. Transplant Proc 2016; 48: 1580-9. 